\title{
Right Spontaneous Hemopneumothorax Associated with SARS-CoV-2 Infection - Case Presentation
}

\author{
Claudiu-Eduard Nistor*, Anca-Pati Cucu, Camelia Stanciu-Găvan*, Adrian Ciuche \\ Department of Thoracic Surgery, University of Medicine and Pharmacy “Carol Davila”, Bucharest, Romania \\ Email address: \\ ncd58@yahoo.com (Claudiu-Eduard N.), ancutapati@gmail.com (Anca-Pati C.), camigavan@gmail.com (C. Stanciu-Găvan), \\ adrianciuche@gmail (A. Ciuche) \\ ${ }^{*}$ Corresponding author
}

\section{To cite this article:}

Claudiu-Eduard Nistor, Anca-Pati Cucu, Camelia Stanciu-Găvan, Adrian Ciuche. Right Spontaneous Hemopneumothorax Associated with SARS-CoV-2 Infection - Case Presentation. International Journal of Cardiovascular and Thoracic Surgery. Vol. 7, No. 1, 2021 , pp. 8-12. doi: $10.11648 /$ j.ijcts.20210701.12

Received: March 31, 2021; Accepted: May 3, 2021; Published: May 14, 2021

\begin{abstract}
Context: SARS-COV2 infection, the respiratory febrile disease firstly described in China in December 2019, which was declared a pandemic on March 11th, 2020, is associated with multiple air and fluid collections. Spontaneous hemopneumothorax in coronavirus disease 19 (COVID 19) patients is a rare clinical entity described as an unusual complication of severe COVID 19 pneumonia. Objective: The authors used the database of a single COVID 19 treatment center only. In our case series, we encountered a patient with particular hemopneumothorax features that we have decided to present. Method: A 51-year-old non-smoker male with fever and cough lasting for 7 days was admitted to the dedicated COVID 19 unit of "Dr. Carol Davila" Central University Military Hospital Bucharest. The patient developed hemopneumothorax on the $14^{\text {th }}$ day since the beginning of the symptoms. The thoracic surgeon performed pleural drainage through minimal pleurotomy allowing the evacuation of both air and fluid. Results: Post interventional computed tomography scan showed the remission of hemopneumothorax. The favorable evolution and the negative SARS COV2 screening throat swab test allowed the discharge of the patient on the 25th day after initial diagnosis. Conclusions: In certain situations, COVID 19 pneumopathy may lead to hemopneumothorax with unpredictable evolution, and only a fast therapeutic intervention can save the patient's life.
\end{abstract}

Keywords: SARS - CoV-2, Spontaneous Hemopneumothorax, Minimal Pleurotomy

\section{Introduction}

SARS COV 2 lung disease may have an unpredictable evolution that might lead, in certain situations, to respiratory failure [1]. The new coronavirus was firstly reported in Wuhan, China in December $2019[2,3]$. The worldwide spread of the disease determined WHO to declare it a public health emergency of international concern on January 30th, 2019, and a pandemic on March 12th, 2020.2[4, 5]. The first case of SARS COV 2 infection was reported in Romania on February 26th, 2020 [6].

Spontaneous hemopneumothorax occurs as an unusual complication of COVID 19 pneumonia [7]. The most efficient imaging technique for COVID 19 patients is computed tomography, due to its high sensitivity [8]. The real-time reverse transcription-polymerase chain reaction is the tool used to confirm SARS COV 2 infection [3].

COVID 19 pulmonary affection along with preexisting lung disease can represent the basis for spontaneous pneumothorax in these patients. The most common symptoms of COVID 19 disease are fever, cough, and dyspnea [7,9]. SARS COV 2 infection is more common in older men with comorbidities, leading to severe pulmonary conditions such as acute respiratory distress syndrome. [10]. The physiopathology of the disease is not currently completely understood [7]. The most common clinical signs are fever $(84,5-92,9 \%)$, dry cough $(40,8-74,4 \%)$, dyspnea $(10,9-80,4 \%)$, fatigue, anorexia and myalgia [11]. The most frequent modification of laboratory analysis findings in current literature includes hypoalbuminemia $(30,5-100,0 \%)$, increased $\mathrm{C}$ reactive protein $(21,8-94,7 \%)$, elevated lactate dehydrogenase $(38,0-76,0 \%), \quad$ lymphopenia $(18,9-67,3 \%)$ and high 
erythrocyte sedimentation rate $(0,0-92,8 \%)$ [12]. Potentially fatal aggravating factors are represented by complications such as severe pneumonia, pulmonary edema [10], pneumothorax, hydropneumothorax, hemopneumothorax [7], pneumomediastinum, subcutaneous emphysema [13], pneumopericardium [14], severe acute respiratory syndrome, or multiple organ failure [12].

COVID 19 pulmonary affection along with preexisting lung disease can represent the cause of secondary spontaneous pneumothorax in these patients.

Secondary spontaneous pneumothorax occurs as a complication of a pre-existent disease: pneumonia, bullous emphysema, cystic fibrosis, lung cancer, asthma, chronic obstructive pulmonary disease, post radic lymphangioleiomyomatosis, or esophageal spontaneous rupture $[15,16]$.

Still, the current classification of secondary spontaneous pneumothorax does not yet include COVID 19 infection as a potential cause.

Sudden aggravation of respiratory symptoms might indicate the necessity for CT re-examination for evaluation of the presence of fluid or air [12].

A retrospective study showed that pneumothorax might occur in $1 \%$ of patients requiring hospital admission [16]. Spontaneous hemopneumothorax is a rare disease that might occur with the accumulation of more than $400 \mathrm{~mL}$ of blood in the pleural space [7]. Currently, only a few cases of spontaneous hemopneumothorax have been described in the literature $[7,11,17]$

Our paper presents the case of a SARS COV2 RT-PCR positive patient with moderate spontaneous hemopneumothorax.

\section{Case Presentation}

\subsection{General Patient Data}

A 51-year-old male presented to our hospital with a three days history of fever, chills, dry cough, perspiration, fatigue, and hemoptysis. The patient was admitted for evaluation, monitoring, and treatment according to COVID 19 protocol. He was a never smoker and has had only a pleural effusion of unknown etiology.

On physical examination, the patient was febrile $39{ }^{\circ} \mathrm{C}$, heart rate and respiration rate were $73 \mathrm{bpm}$, respectively 18 rpm. Blood pressure was $135 / 73 \mathrm{~mm} \mathrm{Hg}$ and the $\mathrm{SpO} 2$ on room air at admission was $90 \%$. He was overweight, his height was $174 \mathrm{~cm}$ with a weight of $86 \mathrm{~kg}$ and body mass index (BMI) of 27,76. Laboratory tests showed elevated levels of CRP (C reactive protein), LDH (Lactate Dehydrogenase), D-dimer, and ferritin (tables 1 and 2).

\subsection{Laboratory Analysis on Admission}

Laboratory test results on admission (hematology and chemistry) are shown in the tables below.

Table 1. Hematology test results.

\begin{tabular}{lll}
\hline Hematology & result & biological reference range \\
\hline WBC & $2,53 \mathrm{k} / \mathrm{microL}$ & $3,80-8,76 \mathrm{k} / \mathrm{microL}$ \\
GR & $1,53 \mathrm{k} / \mathrm{microL}$ & $1,65-4,97 \mathrm{k} / \mathrm{microL}$ \\
Eos & $0,0 \%$ & $0,80-5,50 \%$ \\
Baso & $0,0 \%$ & $0,40-1,40 \%$ \\
Mono & $11,5 \%$ & $4,80-10,20 \%$ \\
Lymph & $0,71 \mathrm{k} / \mathrm{microL}$ & $1,17-3,17 \mathrm{k} / \mathrm{microL}$ \\
TR & $110 \mathrm{k} / \mathrm{microL}$ & $140,00-440,00 \mathrm{k} / \mathrm{microL}$ \\
Hb & $14,1 \mathrm{~g} / \mathrm{dl}$ & $13,20-16,60 \mathrm{~g} / \mathrm{dl}$ \\
Hct & $41,9 \%$ & $40,00-52,00 \%$ \\
Plt & $0,12 \%$ & $0,19-0,36 \%$ \\
Hct & $41,9 \%$ & $40,00-52,00 \%$ \\
VEM & $86,8 \mathrm{fL}$ & $86,00-100,10 \mathrm{fL}$ \\
D_Dimer & $420 \mathrm{ng} / \mathrm{ml}$ & $0-250 \mathrm{ng} / \mathrm{ml}$ \\
\hline
\end{tabular}

Table 2. Blood chemistry test results.

\begin{tabular}{lll}
\hline Blood chemistry & result & biological reference range \\
\hline GLU & $142 \mathrm{mg} / \mathrm{dL}$ & $74,00-100,00 \mathrm{mg} / \mathrm{dL}$ \\
T-bil & $0,30 \mathrm{mg} / \mathrm{dL}$ & $0,30-1,20 \mathrm{mg} / \mathrm{dL}$ \\
$\mathrm{AST}$ & $39 \mathrm{U} / \mathrm{L}$ & $5,00-34,00 \mathrm{U} / \mathrm{L}$ \\
$\mathrm{ALT}$ & $44 \mathrm{U} / \mathrm{L}$ & $0,00-55,00 \mathrm{U} / \mathrm{L}$ \\
$\mathrm{K}$ & $4,60 \mathrm{mmol} / \mathrm{L}$ & $3,50-5,10 \mathrm{mmol} / \mathrm{L}$ \\
$\mathrm{Na}$ & $140,0 \mathrm{mmol} / \mathrm{L}$ & $136,00-145,00 \mathrm{mmol} / \mathrm{L}$ \\
Mg & $1,79 \mathrm{mg} / \mathrm{dL}$ & $1,60-2,60 \mathrm{mg} / \mathrm{dL}$ \\
$\mathrm{Cre}$ & $1,16 \mathrm{mg} / \mathrm{dL}$ & $0,72-1,25 \mathrm{mg} / \mathrm{dL}$ \\
Ureea & $42 \mathrm{mg} / \mathrm{dL}$ & $8,40-25,70 \mathrm{mg} / \mathrm{dL}$ \\
$\gamma$ GT & $98 \mathrm{U} / \mathrm{L}$ & $11,00-59,00 \mathrm{U} / \mathrm{L}$ \\
LD-P & $387 \mathrm{U} / \mathrm{L}$ & $125,00-220,00 \mathrm{U} / \mathrm{L}$ \\
CRP & $51,3 \mathrm{mg} / \mathrm{l}$ & $0,00-5,00 \mathrm{mg} / 1$ \\
Ferritin & $833 \mathrm{mg} / \mathrm{dL}$ & $20,00-250 \mathrm{mg} / \mathrm{dL}$ \\
\hline
\end{tabular}




\subsection{Imaging Examinations}

The clinical and laboratory findings showed a mild inflammatory syndrome associated with respiratory failure. CT scan showed left ground-glass opacities, and right hemopneumothorax (Figure 1).

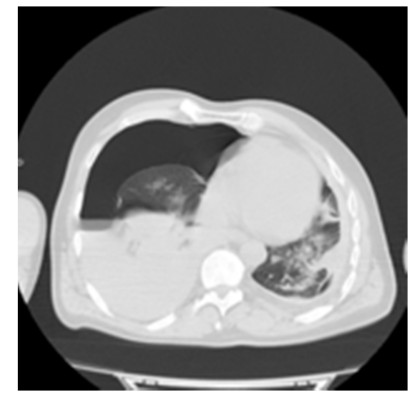

Figure 1. Right hemopneumothorax, left pulmonary consolidation.

\subsection{Therapeutic Attitude}

The patient was treated according to national protocols with Kaletra-lopinavir / ritonavir (200 mg / $50 \mathrm{mg}$ BID on the first treatment day), azithromycin (500 mg QD), paracetamol 10 $\mathrm{mg} / \mathrm{ml} \mathrm{BID}$, and enoxaparin sodium $6000 \mathrm{UI}$ QD. Azithromycin was used for 7 days starting on admission. He also received daily doses of $500 \mathrm{mg}$ methylprednisolone IV.

On the 14th day since admission, his respiratory status worsened suddenly with exacerbation of dyspnea, imposing a new imaging evaluation that revealed a new right hemopneumothorax. The patient's oxygen saturation was $96 \%$ via face mask at a flow of $3 \mathrm{~L} / \mathrm{min}$.

\subsection{Consent Edit Agreement of the Patient}

We performed emergency surgery and drainage of the pleural cavity through right minimally pleurotomy and evacuated both air and $500 \mathrm{~mL}$ of hemorrhagic fluid with no significant hemodynamic impact and constant blood pressure throughout the procedure. Still, the $2 \mathrm{~g} / \mathrm{dL}$ hemoglobin levels decrease caused a slight sinus tachycardia. The hemothorax diagnosis was established using the variation of hemoglobin concentration from the pleural fluid (representing $1 / 2$ of the serum hemoglobin concentration). Control chest X-Ray after pleural drainage showed complete lung re-expansion and absence of hemopneumothorax (Figure 2).

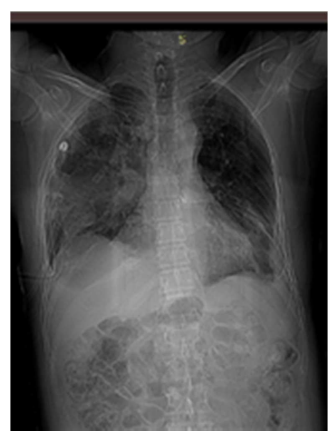

Figure 2. The control radiograph after mounting the drain.

\section{Results}

The favorable evolution after mounting the pleural drain, with complete lung re-expansion and absence of hemorrhagic pleural drainage allowed conservative treatment without the necessity of any surgical hemostasis under general anesthesia. No red cell concentrates transfusion was required, we opted instead for intravenous iron supplementation. Drainage was removed a week after the pleurotomy was performed and supplemental oxygen was administered for 14 days. Intensive respiratory rehabilitation sessions followed discharge.

\section{Discussion}

Spontaneous hemopneumothorax incidence is variable from $2,0 \%$ to $7,3 \%$.[18]. Hemoptysis is rare in COVID 19 patients. $[19,20]$. After the evaluation of the imaging studies showing no other preexisting pleuropulmonary lesions, our hypothesis regarding the cause of spontaneous hemopneumothorax in COVID 19 patients is represented by the existence of inflammatory lesions in interstitial lung tissue affecting the alveolar walls. Apical pulmonary micro blebs rupture with consecutive rupture of visceral pleura along with an apical pleuropulmonary arteriole (without the tendency to hemostasis due to the lack of smooth muscle layerneovascularization) represents the cause of spontaneous hemopneumothorax. Sudden variations of transpulmonary pressure during cough might lead to rupture of alveolar walls with subsequent intrapleural air loss and immediate onset of pneumothorax. COVID 19 pulmonary pathology is represented by diffuse alveolar damage with cellular fibromyxoid exudates, evident desquamation of pneumocytes, and hyaline membrane formation $[13,21]$. The trigger factor of the alveolar rupture is represented by the severe diffuse alveolar lesions associated with dry irritative cough, thus increasing the intrathoracic pressure. [20]. The presence of blood in the pleural cavity suggests the possible existence of a pleuropulmonary arteriole that is damaged during the partial pulmonary collapse, allowing the occurrence of pneumothorax. [7].

Early diagnosis and pleural cavity drainage associated with less severe SARS COV 2 ipsilateral pulmonary lesions allowed fast complete pulmonary re-expansion with blockage of hemorrhagic source and subsequent minimal blood loss who did not necessitate a blood transfusion. Chest drainage mounting was performed through minimally pleurotomy [22]. This was beneficial for fast patient recovery, thus avoiding postoperative post-VATS (video-assisted thoracic surgery) pain syndrome, which might have led to hemodynamic and COVID 19 pneumopathy oxygen-dependent patient-associated respiratory imbalance.

The absence of bleeding, demonstrated by a progressive decrease of pleural drainage and absence of major anemic syndrome, allowed us to use conservative treatment without major surgical hemostasis. 
Early diagnosis was possible because the patient has had already been admitted and monitored for COVID 19 pneumopathy.

The alarm bell that imposed emergency imaging reevaluation was the Sudden aggravation of respiratory symptoms.

Respiratory symptoms are sometimes insidious, resulting in progressive anemia up to significantly low levels of hemoglobin. This demands transfusion of red cell concentrates or autologous blood transfusions using pleural space blood after pleural fluid collection and filtration. Surgical VATS hemostasis, blood vessel clipping, pleural blebs resection, and associated mechanical or chemical pleurodesis are also needed [23, 24].

Minimal pleurotomy for hemodynamically stable patients is adequate in most cases [7, 17, 25]. VATS for control of blood loss is required in patients with active bleeding and hemodynamic instability $[15,26]$.

\section{Conclusions}

COVID 19 pneumopathy might change the therapeutic attitude in hemopneumothorax, necessitating, in certain situations, a conservative treatment- minimal pleurotomy, that could be more beneficial to these patients than any aggressive surgical treatment.

The interdisciplinary collaboration of the thoracic surgeon with the infectious disease and anesthesia specialists is paramount in difficult COVID 19 patients, avoiding possible complications with unfavorable outcomes.

Hospitalization of moderate COVID 19 pneumonia cases is preferred and beneficial due to unexpected changes in the progression of the disease. In certain situations, the use of fast therapeutic measures resulting in alleviation of symptoms might be lifesaving in SARS-CoV-2 patients with unpredictable pulmonary lesions.

As we could see, there are situations when the slightest modification of the patient's status must be carefully monitored, allowing the observation in due time of any possible complications who might benefit from early personalized treatment.

\section{Recommendations}

Early presentation, after the onset of first signs of the disease, in dedicated medical facilities, increases survival in COVID 19 complicated pneumonia. Careful monitoring of the patients allows early recognition of all possible complications and setting in due time a personalized treatment, thus increasing life expectancy.

\section{Author Contributions}

CEN coordinated the study, AC, APC and CG selected the bibliographic materials and all authors collaborated in the elaboration of the manuscript.

\section{Declaration of Conflict of Interest}

The authors declare that they have no competing interests.

\section{Acknowledgements}

The authors thank to all the collaborators and the "Carol Davila" Central Military Emergency University Hospital in Bucharest for their support.

\section{References}

[1] Jakovljevic M, Bjedov S, Jaksic N, Jakovljevic I. COVID-19 Pandemia and Public and Global Mental Health from the Perspective of Global Health Security. Psychiatr Danub 2020; 32: 6-14.

[2] $\mathrm{Lu} \mathrm{H}$, Stratton CW, Tang YW. Outbreak of pneumonia of unknown etiology in Wuhan China: the mystery and the miracle. J Med Virol 2020; published online Jan 16. DOI: 10.1002/jmv. 25678 .

[3] Huang C, Wang Y, Li X, et al. Clinical features of patients infected with 2019 novel coronavirus in Wuhan, China. Lancet 2020; published online Jan 24. https://doi.org/10.1016/S0140 6736(20)30183-5.

[4] WHO: Coronavirus disease 2019 (COVID 19) Situation Report https://www.who.int/emergencies/diseases/novel coronavirus 2019/situation reports/. Updated September 28, 2020.

[5] Hui DS, I Azhar E, Madani TA, et al. The continuing 2019-nCoV epidemic threat of novel coronaviruses to global health - the latest 2019 novel coronavirus outbreak in Wuhan, China. Int J Infect Dis 2020; 91: 264-66.

[6] "Primul caz de coronavirus în România. Suspiciuni despre un al doilea caz în Gorj”. Digi24. Accesat în 26 februarie 2020.

[7] Ann Long, Felipe Grimaldo; Spontaneous hemopneumothorax in a patient with COVID-19; American Journal of Emergency Medicine $\quad 40 \quad$ (2021) 228. e1-228. e2; https://doi.org/10.1016/j.ajem.2020.07.065.

[8] Ruihong Sun, Hongyuan Liu, Xiang Wang; Mediastinal Emphysema, Giant Bulla, and Pneumothorax Developed during the Course of COVID-19 Pneumonia; Case Report Thoracic Imaging; Korean J Radiol 2020; 21 (5): 541-544; https://doi.org/10.3348/kjr.2020.0180.

[9] Centers for Disease Control and Prevention Announcement New ICD 10 Code for Coronavirus 220 2020; 2020 [Accessed 8 JUN 2020].

[10] Nanshan Chen, Min Zhou, Xuan Dong, Jieming Qu, Fengyun Gong, Yang Han, Yang Qiu, Jingli Wang, Ying Liu, Yuan Wei, Jia' an Xia, Ting Yu, Xinxin Zhang, Li Zhang; Epidemiological and clinical characteristics of 99 cases of 2019 novel coronavirus pneumonia in Wuhan, China: a descriptive study; Lancet 2020; 395: 507-13; https://doi.org/10.1016/S0140-6736 (20)30211-7.

[11] Ayşe Vahapoğlu, Bektaş Akpolat, Zuhal Çavuş, Döndü Genç Moralar, Aygen Türkmen; Spontaneous Hemopneumothorax During the Course of COVID-19 Pneumonia; Turk Journal Intensive Care 2020; 18: 46-49; DOI: 10.4274/tybd.galenos.2020.47966. 
[12] Rodriguez-Morales AJ, et al. Clinical, laboratory and imaging features of COVID-19: a systematic review and meta-analysis. Travel Med Infect Dis. 2020; 34: 101623.

[13] Shi Shan, Li Guangming, Lei Wei, Yang Xuedong; Spontaneous pneumomediastinum, pneumothorax and subcutaneous emphysema in COVID-19: case report and literature review; Rev Inst Med Trop São Paulo. 2020; 62: e76; http://doi.org/10.1590/S1678-9946202062076.

[14] Vikisha Hazariwala, Hind Hadid, Denise Kirsch and Cecilia Big; Spontaneous pneumomediastinum, pneumopericardium, pneumothorax and subcutaneous emphysema in patients with COVID-19 pneumonia, a case report; Journal of $\begin{array}{lllll}\text { Cardiothoracic } & \text { Surgery } & \text { (2020) } & 15: & 301\end{array}$ https://doi.org/10.1186/s13019-020-01308-7.

[15] Claudiu-Eduard Nistor, Adrian Ciuche, Camelia Stanciu-Găvan; Spontaneous Pneumothorax - Therapeutic Attitude - Brief Review; International Journal of Cardiovascular and Thoracic Surgery 2020; 6 (4): 49-53; $\mathrm{http}: / / \mathrm{www}$. sciencepublishinggroup.com/j/ijcts; doi: 10.11648/j.ijcts.20200604.12.

[16] Mansoor Hameed, Wasim Jamal, Muhammad Yousaf, Merlin Thomas, Irfan Ul Haq, Shakeel Ahmed, Mushtaq Ahmad, Mohamad Khatib; Pneumothorax In Covid-19 Pneumonia: A case series; Respiratory Medicine Case Reports 31; (2020); 101265; https://doi.org/10.1016/j.rmcr.2020.101265.

[17] Omer Salah, Mohannad Faisal, Israa Alshahwani, Abdelhaleem Elhiday 1. Internal Medicine, Hamad Medical Corporation, Doha, QAT 2; Bilateral Hemopneumothorax in COVID-19; Cureus 2020; 12 (9): e10314. DOI 10.7759/cureus. 10314 .

[18] Hsu NY, Shih CS, Hsu CP, Chen PR. Spontaneous hemopneumothorax revisited: clinical approach and systemic review of the literature. Ann Thorac Surg. 2005; 80 (5): 185963.

[19] Guan WJ, Ni ZY, Hu Y, Liang WH, Ou CQ, He JX, et al. Clinical characteristics of coronavirus disease 2019 in China. N Engl J Med 2020; 382: 1708-20.

[20] Lin X, Gong Z, Xiao Z, Xiong J, Fan B, Liu J. Novel Coronavirus Pneumonia Outbreak in 2019: Computed Tomographic Findings in Two Cases. Korean J Radiol 2020; 21: 365-8.

[21] Xu Z, Shi L, Wang Y, Zhang J, Huang L, Zhang C, et al. Pathological findings of COVID-19 associated with acute respiratory distress syndrome. Lancet Respir Med. 2020; 8: 420-2.

[22] Nistor Cl, Ciuche A, Davidescu M, Horvat T; Pleurotomy - a surgical intervention at the hand of the general surgeon; 2009 Chirurgia; 104 (3), 323-328.

[23] C Nistor, AE Ranetti, A Ciuche, D Pantile, LM Constantin, R Brincoveanu; Betadine (r) in chemical pleurodesis; Farmacia, 2014; 62 (5), 897-906; ISSN 0014-8237 (IF-1,251).

[24] A Ciuche, C Nistor, D Pantile, D Marin, A Tudose; Spontaneous pneumothorax in a case of pulmonary langerhans cell histiocytosis; Mædica, 2011; 6 (3), 204.

[25] Flower L, Carter JL, Rosales Lopez J, Henry AM. Tension pneumothorax in a patient with COVID-19. BMJ Case Rep. 2020; 13: e235861.

[26] Kim ES, Kang JY, Pyo CH, Jeon EY, Lee WB. 12-year experience of spontaneous hemopneumothorax. Ann Thorac Cardiovasc Surg. 2008; 14 (3): 149-53. 